\title{
ФАКТОРЫ УПРАВЛЕНИЯ ЧЕЛОВЕЧЕСКИМИ РЕСУРСАМИ В ЭКОНОМИЧЕСКОМ ПРОСТРАНСТВЕ РОССИИ
}

\author{
Щетинина Дарья Павловна
}

На сегодняшний день одной из наиболее актуальных областей теоретических и практических интересов является поведенческая экономика, исследующая психологические закономерности поведения человека, предопределяющие его экономические решения.

В рамках этого направления, в данной статье предпринята попытка объединить психологический и экономический подходы к изучению основных факторов управления человеческими ресурсами и человеческим капиталом в экономическом пространстве России, которые были объединены в четыре группы: ситуационно-средовые, личностные, сочиально-экономические и политические факторы и организачионно-управленческие факторы.

Поскольку управление человеческими ресурсами осуществляется в экономическом пространстве страны, индикаторы мониторинга развития человеческих ресурсов и человеческого капитала должны представлять собой систему показателей, включающую показатели экономической плотности, показатели размещения и качества населения и экономической деятельности, показатели интенсивности социально-экономических взаимосвязей и показатели психологического состояния населения.

Определяется роль человеческих ресурсов как движущей силы в повышении уровня и качества жизни людей, выравнивании условий сочиальноэкономического развития страны и регионов, и обосновывается основная роль инвестиций в человеческий капитал как ключевого фактора инновачионного развития российской экономики.

Ключевые слова: человеческие ресурсы, человеческий капитал, образование, знания, инвестиции, экономическое пространство, регион, трудовые ресурсы, трудовой потенциал, индекс развития человеческого потенциала (ИРЧП), интегральный показатель человеческого капитала (ИПЧК).

Экономический кризис продолжает усугублять разрыв между регионами по основным показателям социального и экономического развития, снижая и увеличивая разницу в уровне и качестве жизни населения. 
Ограниченные возможности государства способствуют передаче решения ряда проблем на региональный уровень. Поскольку регион функционирует в рамках более сложной системы национального экономического пространства, это предопределяет выполнение двойственной функции региональных экономических систем. Экономическая функция предполагает развитие в регионе отраслей производства с целью получения экономического эффекта в масштабах всего национального хозяйства. Социально-экономическая функция основывается на принципе зависимости уровня жизни населения от эффективности функционирования региональной экономики, что предполагает рассмотрение региона как социально-экономического комплекса, основными звеньями которого выступают сбалансированные материальное производство и социальная сфера, как основная база, определяющая качество жизни людей и создающая благоприятную среду для воспроизводства человеческих ресурсов на новом качественном уровне [16, с.14].

Основой эффективного управления любой экономической системой становится управление человеческими ресурсами.

И здесь основную роль играет теория человеческого капитала, которая дает представление о роли человеческих ресурсов как фактора повышения национального благосостояния и источника экономического роста, а значит понимания рентабельности инвестиций в человека.

Изменение концепции управления человеческими ресурсами на макро-, мезо- и микроуровнях от затратного подхода к инвестиционному задает и новые ориентиры бизнес-агентам, участникам рынка образовательных услуг для перехода от стратегии управления затратами к стратегии проектного управления результатами, что можно осуществить лишь консолидированными усилиями государства и бизнес-сообщества на всех уровнях социально-экономической системы управления человеческими ресурсами [7, с. 134].

Исследованиями экономической сущности человека и его места в экономической системе занимались такие экономисты, как: Г. Беккер, Ф. Лист, А. Маршал, К. Маркс, Дж. Миль, В. Парето, Д. Рикардо, А. Смит, Ж. Б. Сэй, И. Тюнен, Дж. С. Уолш, И. Фишер, Т. Шульц и др.

В основе теории человеческого капитала лежит исследование нерыночных форм деятельности - образования, здравоохранения, охраны труда, географической миграции, планирования семьи и брака, рождения детей, религии и т. д.

Психологическое измерение человеческого капитала появилось как развитие психодиагностических методов профессионального отбора, построенных на теоретических концепциях ученых ленинградской психологической школы - Б. Г. Ананьева, В. А. Ганзена, Г. В. Суходольского [14]. 
Основа данного исследования состоит в системном описании реального психолого-соматического состояния человека и показателей его жизнеспособности, работоспособности, способности к обучению и способности воспринимать инновации.

Человеческий капитал включает в себя весь объем знаний, умений и навыков, обусловленных особенностями интеллекта, поведения и мотивации, врожденными и приобретенными талантами, имеющих экономическую ценность.

Таким образом, человеческий капитал определяется способностями его носителя, с экономической точки зрения - способностью производить товары и услуги, а с психологической - скрытыми реальными возможностями и желаниями исполнять эту работу.

На сегодняшний день Индекс развития человеческого потенциала (ИРчП) является основным индикатором для мониторинга развития человеческого капитала (табл. 1) [11, с. 16-19; 20].

Таблича 1

Индекс развития человеческого потенциала ряда стран и регионов России (2013 г.)

\begin{tabular}{|c|c|c|c|c|c|}
\hline Mecmo & Страна & ИЧР & Mecmo & Регион & ИЧР \\
\hline \multicolumn{3}{|c|}{ Страны с очень высоким уровнем ИЧР } & \multicolumn{3}{|c|}{ Регионы с очень высоким уровнем ИЧР } \\
\hline 1 & Норвегия & 0,944 & 1 & Москва & 0,931 \\
\hline 2 & Австралия & 0,933 & 2 & Санкт-Петербург & 0,887 \\
\hline 3 & Швейцария & 0,917 & 3 & Тюменская область & 0,877 \\
\hline 5 & США & 0,914 & 4 & Сахалинская область & 0,871 \\
\hline 6 & Германия & 0,911 & 40 & Ростовская область & 0,816 \\
\hline \multicolumn{3}{|c|}{ Страны с высоким уровнем ИЧР } & \multicolumn{3}{|c|}{ Регионы с высоким уровнем ИЧР } \\
\hline 57 & Россия & 0,778 & 63 & Республика Адыгея & 0,799 \\
\hline 69 & Турция & 0,659 & 64 & Брянская область & 0,798 \\
\hline
\end{tabular}

Как известно, рейтинг Индекса развития человеческого потенциала разбит на четыре группы: страны с очень высоким, высоким, со средним и страны с низким ИЧР. Российская Федерация, занимая 57 место, относится к группе стран с высоким уровнем развития человеческого потенциала. Несмотря на большой разброс значений индекса по регионам России, большинство субъектов федерации имеет очень высокий ИЧР (Москва, Санкт-Петербург, Тюменская, Свердловская, Ростовская области), а более проблемные регионы (Северного Кавказа) - высокий ИЧР, хотя еще в 2009 г. большинство регионов России имело средний ИЧР.

Несмотря на то, что Индекс развития человеческого потенциала отражает влияние на человеческий капитал наиболее важных социально- 
экономических процессов (здоровье и долголетие, доступ к образованию и достойный уровень жизни), пробел в оценке психологической составляющей человеческого капитала существенно снижает его достоверность и полноту.

К тому же, поскольку мы говорим об управлении человеческими ресурсами в регионе как составной части единого экономического пространства страны, а основными характеристиками экономического пространства являются плотность, размещение и связанность, то индикаторы мониторинга развития человеческих ресурсов и человеческого капитала должны опираться на следующие параметры:

- показатели численности населения, объема ВВП на душу населения и т. д. на единицу площади, т. е. показатели экономической плотности;

- показатели распределения населения и экономической деятельности (качество, равномерность, дифференциация, концентрация);

- показатели интенсивности социально-экономических взаимосвязей между частями и элементами пространства (условия мобильности капитала и людей, определяемые развитием информационных, транспортных и коммуникационных сетей) [3].

Управление человеческими ресурсами в регионе должно быть относительно устойчивой системой социально-психологических механизмов взаимодействия субъекта и объекта управления, в процессе реализации информационного воздействия на управленческие функции и осуществляться с помощью воздействия на факторы, способствующие повышению национального богатства страны и уровня благосостояния населения.

Традиционно выделяют следующие макроэкономические и региональные факторы управления человеческими ресурсами и капиталом: этап развития социально-экономической системы, хозяйственные механизмы, воспроизводство, благосостояние, здоровье, образование населения, жилищные условия, духовная жизнь и культура, обеспеченность товарами и услугами, социальное обеспечение, экология, безопасность, права человека, подготовка квалифицированной рабочей силы, трудовое законодательство, распределение рабочей силы по отраслям и регионам, природно-климатические условия, развитость социально-бытовой инфраструктуры, состояние регионального рынка труда, мобильность населения и т. д., которые можно объединить в четыре группы факторов.

Первая группа - ситуационно-средовые факторы. В этой группе факторов среда представляет собой природно-социокультурный феномен, выявляющий механизм возникновения ситуации развития личности.

Высокая разреженность экономического пространства России становится огромной проблемой в связи с тем, что большая часть пространства имеет 
крайне низкую плотность населения и экономической жизни, и, соответственно, малую рыночную емкость. Площадь России занимает, приблизительно, 1/8 часть Земли, при этом численность населения неуклонно сокращается, а неравномерное распределение населения по регионам еще больше усугубляет ситуацию: так, по последним данным численность населения возросла только в Центральном и Южном федеральных округах, и то в основном за счет миграции (табл. 2) [8, 9].

Таблица 2

Плотность населения ряда стран в 2014 г.

\begin{tabular}{|c|c|c|c|}
\hline No & Страна & $\begin{array}{c}\text { Население (чел.) по оценке на } \\
\mathbf{2 0 1 4} \text { г. }\end{array}$ & $\begin{array}{c}\text { Плотность населения } \\
\mathbf{6} \mathbf{2 0 1 1} \text { 2. }\end{array}$ \\
\hline 1 & Россия & 142470272 & 8,10 \\
\hline 2 & США & 318892103 & 33,45 \\
\hline 3 & Китай & 1355692576 & 139,29 \\
\hline 4 & Индия & 1236344631 & 361,72 \\
\hline
\end{tabular}

Территориальная протяженность России, связанная с ней пространственная удаленность ряда регионов от федерального центра и приграничное положение оказывают сильное влияние на приграничные территории, особенно регионы Дальнего Востока. Кроме того, что соседние государства в последние десятилетия развиваются в 2-3 раза быстрее, чем Дальневосточный регион, особую опасность представляют различия в плотности населения (4,2 чел./кв. км. в Дальневосточном федеральном округе; 139,29 чел./кв. км. в Китае; 334,74 чел./кв. км. в Японии; 495,07 чел./кв. км. в Южной Корее). В этих условиях особенно актуальными становятся проблемы нерегулируемой миграции иностранных граждан и обеспечения территориальной целостности России.

Территориальная структура российского хозяйства состоит из нескольких крупных экономических районов и центров, разделенных протяженными экономическими «пустотами». Высокие транспортные тарифы, вызывающие дистанционную обособленность территорий, вместе с либерализацией внешнеэкономических связей, а также политика региональных властей, направленная на защиту региональной экономики, приводят к ослаблению межрегиональных связей, углубляя дезинтеграцию российского социальноэкономического пространства. В результате в структуре экономических связей субъектов РФ заметно понизилась доля межрегиональных связей и возросла доля внутрирегиональных и внешнеэкономических связей.

Кроме того, более половины территории России находится в суровых природно-климатических условиях, которые обусловливают сугубо сырьевую 
моноспециализацию хозяйства регионов, неразвитость инфраструктуры, низкую плотность населения и продолжающуюся миграцию населения в более благоприятные регионы или, иными словами, происходит деградация экономического и социального потенциала территорий, что понижает шансы на возрождение.

На сегодняшнем этапе, социально-экономическая политика должна быть направлена на наращивание воспроизводственного потенциала регионов и городов методами обустройства территории и развития человеческого потенциала. Особое внимание необходимо уделить дорогам и жилью, создающим наибольший мультипликативный эффект, т. к. обширная территория требует современную транспортную систему, отвечающую всем требованиям: масштабам страны, суровым климатическим условиям и т. д.

Россию принято считать многонациональной страной со сложными межкультурными взаимодействиями. Хотя подавляющее большинство населения страны (77 \%) - русские, влияние культуры различных народов, в том числе отношения к работе, представления о взаимоотношениях внутри рабочей группой, понятия справедливости и честности в различных трудовых ситуациях и т. д. неоспоримо. Поэтому постоянно остаются открытыми вопросы финансирования и этнокультурного развития народов, населяющих Россию, а также вопросы культурной и языковой адаптации мигрантов, совершенствования миграционной политики, законодательства и правоприменительной практики в миграционной сфере. Например, финансирование в рамках федеральной целевой программы социально-экономического развития народов в Крыму и Севастополе до 2020 г. превысит 10 миллиардов рублей. Тем не менее, основной идеей правительства является признание основополагающей роли культурно-нравственного потенциала и сохранение русской культурной доминанты, отсюда и объявление 2014 года Годом культуры, и разработка по указанию президента Российской Федерации «Основ культурной политики».

Вторая группа факторов - личностные, они объединяют факторы, формирующие поведение человека как экономического субъекта.

Несмотря на существование исследований, посвященных оценке личности, психологических качеств человеческого капитала, по-прежнему нет четкой концепции как их «материализовать».

Для определения функциональных возможностей человеческого капитала А. И. Юрьев предлагает использовать интегральный показатель человеческого капитала (ИПЧК), объединяющий четыре вторичных индекса и состоящий из параметров его реального поведения: жизнеспособности человека (сокращение ухода из жизни мужчин в рабочем возрасте и др.), работоспособности (повышение профессиональной конкурентоспособности 
до уровня современных требований и др.), способности своевременно адаптироваться к глобальным изменениям в мире (изменение в мировоззрении общества, организации общества, новых формах управления обществом и т. п.), способности к обучению (обучение новым профессиям, самостоятельное получение новых научных и культурных знаний и др.), которые в свою очередь интегрируют от 6 до 14 первичных показателей. Так, по расчетам профессора А. И. Юрьева, интегральный показатель человеческого капитала в большинстве регионов России не превышает 0,5 по шкале от 0 до 1. Самые низкие показатели человеческого капитала - это работоспособность $(0,38)$ и способность к обучению $(0,42)$ [17].

Соответственно, основными негативными факторами, влияющими на качество человеческого капитала, являются проблемы, связанные со здоровьем человека, соблюдением режима труда и отдыха, питания, а также стрессом и высоким уровнем личной тревожности, связанные с адаптацией человека к изменениям в стране и мире.

В структуре причин смерти по данным Росстата в 2013 г. первое место по-прежнему занимают болезни системы кровообращения - 53,2 \%, на втором месте - новообразования - 15,4 \% на третьем - внешние причины - 9,1\%.

Так, если рассматривать данные, связанные с социально-психологическим состоянием населения, на 4,4 \% возросла заболеваемость нервной системы и органов чувств, на 0,8 \% возросла заболеваемость системы кровообращения, в 1,3 раза выросла смертность от язвенной болезни, в 1,8 раз - от несчастных случаев, травм, отравлений. Также, по некоторым оценкам, примерно 70 \% россиян живет в состоянии постоянного стресса, а кризис 2014 г., санкции и война в Украине еще усугубляют ситуацию.

Несмотря на то, что за 2013 г. показатель ожидаемой продолжительности предстоящей жизни при рождении вырос на 0,53 года и составил 70,8 года, а у женщин продолжительность жизни достигла исторического максимума для нашей страны - 76,6 лет, нельзя не отметить наличие существенной дифференциации показателей в региональном отношении.

Как мы уже говорили, вторым компонентом ИЧР является уровень достигнутого образования, и именно он обуславливает нахождение России в группе с высоким уровнем ИЧР. Несмотря на то, что уровень грамотности взрослого населения в России составляет 99 \%, происходящие в мире и России изменения вызвали необходимость формирования новой парадигмы результата образования, ориентированного на компетенции (competencebased education - (BE) как социально-личностно-поведенческий феномен, проявляющийся в совокупности мотивационно-ценностных, когнитивных составляющих личности [8, с. 53-57]. 
Качество образования - это фундаментальность и востребованность полученных знаний, т. е. возможность их применения для достижения поставленной цели и повышения качества жизни.

Знания (интеллект) являются основой человеческого капитала и выступают как новая мера оценки стоимости организаций, а обмен знаниями - является основой организационной стратегии.

Несмотря на то, что нельзя выявить четкую пропорцию между инвестициями в знания на входе и на выходе, человеческий капитал требует постоянных и непрерывных вложений для получения существенного мультипликативного эффекта в сочетании с другими факторами производства. Соответственно, главной психологической задачей управления человеческим капиталом является нахождение условий и повышение уровня инвестиционной привлекательности образования.

Третья группа факторов включает в себя социально-экономические и политические факторы.

Эффективность экономического развития регионов и их населения напрямую зависит от их способности адаптироваться к современным условиям, особенно в период кризиса.

Несмотря на дифференциацию регионов по уровню экономического развития, за последние 10 лет ситуация существенно улучшилась: так, если в 2005 г. отношение душевого ВРП самой «богатой» нефтегазодобывающей Тюменской области и самой «бедной» Республики Ингушетия достигало 30 раз, то к 2012 г. оно сократилось до 13 раз, как следствие централизации и перераспределения нефтегазовых доходов [5, с. 140].

За счет экономического роста и увеличения объемов потребления за последние годы наблюдалось заметное сокращение масштабов бедности. Но по данным Росстата, падение уровня жизни и реальных доходов населения, вызванное кризисом и падением рубля, в ноябре 2014 г. составило 4,7 \%, а по неофициальным данным - превысило 15 \%. И это только начало, а реальное положение дел можно будет оценить лишь в следующем году.

Несмотря на то, что Минэкономразвития по последним прогнозам повысил уровень безработицы на 2015 г. до 5,9 \%, это меньше, чем в большинстве европейских стран, и в России на сегодняшний день имеется 1,8 млн. вакансий. Вместе с тем, это будет происходить на фоне общего снижения численности занятых практически на миллион человек к 2015 г. всего за три года до 68,6 миллиона, что требует для обеспечения роста экономики повышение производительности труда на 17,5 \% [11]. Следовательно, в условиях жесткой конкуренции необходимы: изменение структуры и форм занятости, дифференциация персонала и формирование «внутреннего рынка труда», т. е. использование новых методов управления человеческими ресурсами, 
способствующих повышению производительности труда и завоеванию организациями конкурентной мощи.

Одним из основных инструментов в реализации социально-экономической политики страны и регионов становится информация как источник формирования общественного сознания, воспитания граждан и управления человеческими ресурсами и капиталом.

К основным путям повышения эффективности информационного воздействия в процессе управления человеческими ресурсами, снижения социальных страхов у населения относят: совершенствование информационного обеспечения управленческого процесса; усиление позитивного влияния информации на человеческие ресурсы; формирование и развитие информационно-управленческой культуры субъектов управления; развитие государственных и региональных СМИ, которые призваны объединять людей вокруг конструктивных путей выхода из кризиса.

Четвертая группа - организационно-управленческие факторы.

Управление человеческими ресурсами страны и регионов всех уровней возможно лишь при наличии законодательных, организационных и информационных основ, обеспечивающих возможности принятия и воплощения в жизнь управленческих решений.

Законодательные основы управления персоналом опираются на все нормативно-правовые акты, регулирующие трудовые отношения, а также нормативные акты смежных областей, например: пенсионное законодательство, нормативные акты о защите социальных и трудовых прав отдельных категорий граждан и т. д. Правовое обеспечение системы управления персоналом осуществляется как на уровне федерального и регионального законодательства - акты центрального регулирования, так и на уровне организации - акты локального регулирования.

При постоянном сокращении численности трудоспособного населения на фоне роста численности пенсионеров, продолжительности жизни и наличия большого количества льготников, выходящих на пенсию раньше времени, государство ищет дополнительные источники доходов в Пенсионный фонд, нагрузка на который ежегодно увеличивается. И, хотя президент выступает с принципиальной позицией о неповышении пенсионного возраста, пенсионный фонд уже проводит программу по стимулированию более позднего выхода на пенсию, путем повышения пенсий пенсионерам, оформляющим пенсию позже, чем в 55 и 60 лет соответственно, и за счет повышения минимального трудового стажа с 5 лет на сегодняшний день и до 15 лет к 2025 г. Также государство планирует увеличить пенсионный возраст для военнослужащих армии и флота и силовых ведомств на 5 лет. И все-таки необходимо понимать, что увеличение пенсионного возраста возможно 
лишь в тех странах, где фиксируется высокий уровень продолжительности жизни, иначе на пенсию будет выходить лишь небольшой процент граждан, доживших до пенсионного возраста.

Флексибилизация российского рынка труда характеризуется смягчением трудового законодательства в пользу работодателей, стимулированием создания рабочих мест с нестандартным режимом рабочего времени (занятость по временным контрактам, сезонная занятость, неполная занятость, занятость по режимам неполного рабочего времени и т. д.) и осложнена слабыми социальными гарантиями со стороны государства. То есть, гибкость режима труда, с одной стороны, является инструментом повышения эффективности производства, а с другой позволяет организациям манипулировать законами и инструкциями по предоставлению равных возможностей в области занятости, порядка увольнения, охраны здоровья и техники безопасности на производстве, защиты прав временных работников и тех, кто занят неполный рабочий день, а также многих других ключевых факторов, определяющих трудовые отношения.

Таким образом, возрастает роль государства и регионов в регулировании системы взаимоотношений с работниками, включающая степень участия государства в разрешении трудовых споров и конфликтов, уровень профсоюзного движения и сложившихся взаимоотношений между профсоюзами и компаниями-работодателями.

Анализ основных факторов управления человеческими ресурсами в экономическом пространстве России показал, что информация, научные знания, профессиональный и культурный потенциал общества как интеллектуальные ресурсы определяют структуру национальной экономики.

И совершенно очевидно, что формирование человеческого капитала - это задача государственной социальной политики, в основе которой должно быть личностно-формирующее и личностно-развивающее содержание механизма функционирования общества. То есть, первоочередной задачей становится развитие личностно-профессионального потенциала человека.

Следует отметить, что мы рассмотрели общие, или внешние факторы управления человеческими ресурсами и капиталом в экономическом пространстве страны и регионах (макроуровень), но немаловажную роль играют специфические или внутриорганизационные факторы, к которым относят уровень организации и управления производством в самом коллективе, его социально-психологический климат, личностный состав (микроуровень).

Очевидно, что наиболее эффективным в современных условиях, при формировании стратегии управления человеческими ресурсами, будет использование, адаптация и развитие накопленного человеческого капитала на всех уровнях. 


\section{Литература}

1. Армстронг М. Стратегическое управление человеческими ресурсами: Пер. с англ. - М.: ИНФРА-М, 2002.

2. Ганзен В. А. Системные описания в психологии. - Л.: Изд-во Ленингр. ун-та, 1984. - 176 с.

3. Гранберг А. Г. Основы региональной экономики: учебник для вузов; 4-е изд. - М.: Изд. дом ГУ ВШЭ, 2004.

4. Джой-Меттьюз Д., Меггинсон Д., Сюрте М. Развитие человеческих ресурсов. - М.: Эксмо, 2006.

5. Доклад о человеческом развитии в Российской Федерации за 2013 г. / Под общей редакцией С. Н. Бобылева. - М.: ООО «РА ИЛЬФ», 2013. - 202 с.

6. Капелюшников Р. И. Экономический подход Гэри Беккера к человеческому поведению // США: экономика, политика, идеология. - 1993. № 11.

7. Маличенко И. П. Модернизация профессионального образования в условиях государственно-частного партнерства // Проблемы теории и практики управления. - 2014. - № 10.

8. Меньщенина Е. А. Мониторинг предпочтений работодателей и перспективы совершенствования модели компетенций бакалавриата по образовательному направлению «Управление персоналом» // Управление персоналом и интеллектуальными ресурсами России. - 2014. - № 5.

9. Оценка численности населения стран мира на 2014 г. // URL: http:// total-rating.ru/18-chislennost-naseleniya-stran-mira.html

10. Плотность населения территорий мира // URL: http://worldgeo.ru/ lists/?id=16

11. Прогноз экономического развития России на 2015 г. // URL: http:// economy.gov.ru/minec/main

12. Сахарова О. Н. Индекс развития человеческого потенциала: место России в современном мире // Вестник Таганрогского института управления и экономики. - 2014. - № 1.

13. Синявская О. В. Основные факторы воспроизводства человеческого капитала // Экономическая социология. - 2001. - Т. 2. - № 1.

14. Стратегическая психология глобализации: Психология человеческого капитала: Учеб. пособие / Под науч. ред. д-ра психол. наук, проф. А. И. Юрьева. - СПб.: Logos, 2006. - 512 с.

15. Харрис Р. Психология массовых коммуникаций. - М.: Инфра-М, 2003. 417 c.

16. Щетинина Д. П. Влияние неоднородности экономического пространства на индикаторы региональной динамики: дисс. ... канд. экон. наук. - Ростов н/Д, 2006. 
17. Юрьев А. И. Опыт психологического измерения человеческого капитала // URL: http://www.yuriev.spb.ru

18. Becker M. Personalentwicklung - Bildung, Forderung und Organisationsentwicklung in Theorie und Praxis. - Stuttgart, 2002.

19. Becker M. Personalentwicklung - Schaffer-Poeschel Verlag. - Stuttgart, 2005.

20. Human Development Report 2014 // URL: http://hdr.undp.org/en

21. Rynes S. L., Milkovich G. T. Current Issues in Human Resource Management: Commentary and Readings. - Texas, 1986. 
32. Stroop J. R. Studies of interference in serial verbal reactions // Journal of Experimental Psychology: General, 1992, Volume 121, Issue 1, pp. 15-23.

33. Tajfel H., Richardson A., Everstine L. Individual consistencies categorizing: A study in judgment behavior // Journal of Personality, 1964, Volume 32, Issue 1, pp. 90-108.

34. Wagener D. K., Hogarty G. E., Goldstein M. J., Asarnow R. A., Browne A. Information processing and communication deviances in schizophrenics patients and their mothers // Psychiatry Research, 1986, Volume 18, Issue 4, pp. 365-377.

\section{FACTORS OF HUMAN RESOURSE MANAGEMENT IN THE ECONOMIC SPACE OF RUSSIA}

\section{Schetinina Darya Pavlovna}

Behavioural economics investigating psychological regularities of behavior of the person predetermining his/her economic decisions is one of the most urgent areas of theoretical and practical interests today.

Within the limits of this area, in this article the author makes an attempt to combine psychological and economic approaches to studying the main factors of human resource and human capital management in the economic space of Russia which were united in four groups: situational-environmental, personal, social-economic and political factors and organizational-management factors.

Since human resource management is carried out in the economic space of the country, indicators of monitoring human resource and human capital development must be a system of characteristics including characteristics of economic density, characteristics of population distribution and quality and economic activity, characteristics of the intensity of socio-economic relationships and characteristics of the psychological state of the population.

The author defines the role of human resources as a driving force in raising people's standard of living and quality of life, levelling of conditions of social and economic development of the country and regions and substantiates the main role of investment in human capital as a key factor of the innovative development of the Russian economy.

Keywords: human resources, human capital, education, knowledge, investment, economic space, region, manpower, labor potential, human development index (HDI), integral indicator of human capital (IIHC). 


\section{References}

1. Armstrong M. Strategicheskoe upravlenie chelovecheskimi resursami [Strategic human resource management]. Moscow, INFRA-M Publ., 2002.

2. Ganzen V. A. Sistemnye opisaniia v psikhologii [System descriptions in psychology]. Leningrad, Leningrad University Publ., 1984, 176 p.

3. Granberg A. G. Osnovy regional'noi ekonomiki: uchebnik dlia vuzov [Fundamentals of regional economy: textbook for universities]. Moscow, Higher School of Economics State University Publ., 2004.

4. Joy-Matthews J., Megginson D., Surtees M. Razvitie chelovecheskikh resursov [Human resources development]. Moscow, Eksmo Publ., 2006.

5. Doklad o chelovecheskom razvitii v Rossiiskoi Federatsii za 2013 g. / Pod obshchei redaktsiei S. N. Bobyleva [Human development report for the Russian Federation 2013 / Under the general editorship S. N. Bobyliov]. - M.: "RA IL'F" Publ., 2013, 202 p.

6. Kapeliushnikov R. I. Ekonomicheskii podkhod Geri Bekkera k chelovecheskomu povedeniiu [H. Becker's economic approach to human behavior]. SShA: ekonomika, politika, ideologiia - USA: Economics, Politics, Ideology, 1993, no. 11.

7. Malichenko I. P. Modernizatsiia professional'nogo obrazovaniia v usloviiakh gosudarstvenno-chastnogo partnerstva [Modernization of professional education in the conditions of public-private partnership]. Problemy teorii i praktiki upravleniia - Problems of the Theory and Practice of Management, 2014, no. 10.

8. Men'shenina E. Monitoring predpochtenii rabotodatelei i perspektivy sovershenstvovaniia modeli kompetentsii bakalavriata po obrazovatel'nomu napravleniiu“Upravlenie personalom" [Monitoring of employers' preferences and perspectives of improving the model of competences of undergraduate studies in the educational field "Human resource management"]. Upravlenie personalom i intellektual'nymi resursami Rossii - Intellectual Resources and Human Resource Management in Russia, 2014, no. 5.

9. The estimated population of countries of the world in 2014. Available at: http://total-rating.ru/18-chislennost-naseleniya-stran-mira.html

10. Population density areas of the world. Available at: http://worldgeo.ru/ lists/? id=16

11. Forecast of Russian economy development for 2015. Available at: //URL: http://economy.gov.ru/minec/main

12. Sakharova O. N. Indeks razvitiia chelovecheskogo potentsiala: mesto Rossii v sovremennom mire [The human development index: the place of Russia in the modern world]. Vestnik Taganrogskogo instituta upravleniia i ekonomikiBulletin of Taganrog Institute of Management and Economics, 2014, no. 1. 
13. Siniavskaia O.V. Osnovnye faktory vosproizvodstva chelovecheskogo kapitala [The main factors of the reproduction of human capital]. Ekonomicheskaia sotsiologiia - Economic Sociology, 2001, V. 2, no. 1.

14. Strategicheskaia psikhologiia globalizatsii: Psikhologiia chelovecheskogo kapitala:Ucheb. posobie [Strategic psychology of globalization: the psychology of human capital: textbook]. St. Petersburg, Logos, 2006 Publ., 512 p.

15. Harris R. Psikhologiia massovykh kommunikatsii [The psychology of mass communication]. Moscow, Infra-M, 2003, 417 p.

16. Shchetinina D. P. Vliianie neodnorodnosti ekonomicheskogo prostranstva na indikatory regional'noi dinamiki. Diss. cand. econom. nauk [Influence of the heterogeneity of economic space on indicators of regional dynamics. Cand. econom. sci. diss]. Rostov-on-Don, 2006.

17. lur'ev A. I. Experience of psychological measurement of human capital. Available at: http://www.yuriev.spb.ru

18. Becker M. Personalentwicklung - Bildung, Forderung und Organisationsentwicklung in Theorie und Praxis, Stuttgart, 2002.

19. Becker M. Personalentwicklung - Schaffer-Poeschel Verlag Stuttgart, 2005.

20. Human Development Report 2014 // URL: http://hdr.undp.org/

21. Rynes S. L., Milkovich G. T. Current Issues in Human Resource Management: Commentary and Readings. Texas, 1986.

\section{PUNISHMENT INDIVIDUALIZATION OF MINORS IN ENFORCEMENT ACTIVITIES: PSYCHOLOGICAL ASPECTS}

\section{Goldobina Viktoria Sergeevna}

The article considers the issues of accounting psychological characteristics of a person with the individualization of the punishment appointed by minors. The complexity of studying the personality of the teenager, the perception of information, and behavioral aspects in terms of the crime situation due to age-related features, which are characteristic of juvenile age. The importance of accounting for individual characteristics is determined by the fact that any, including atypical behavior of a minor, both in terms of the crime, and after that, depends on the properties of the identity of the juvenile, which are often neglected in practical enforcement.

It is pointed out the need to consider not only the socio-demographic, but psychological aspects of personality, which affect consciousness (awareness) 